\title{
BIBLIOMETRIC APPROACH TO TRACKING THE CONCEPT OF INTERNATIONAL COMPETITIVENESS
}

\author{
Magdalena OLCZYK \\ Department of Economics, Faculty of Management and Economics, \\ Gdansk University of Technology, Narutowicza 11/12, 80-233, Gdansk, Poland \\ E-mail: Magdalena.Olczyk@zie.pg.gda.pl
}

Received 05 February 2016; accepted 09 September 2016

\begin{abstract}
The main aim of paper is to identify the growth pattern in the international competitiveness literature, its core publications and key research domains on the basis of bibliometric data from the years 1945-2015. Citation data is collected from the ISI Web of Science Website, Scopus and Google Scholar, and analysed using HistCite, Pajek and VOSviewer software. Bibliometric indicators, network citation, key-route path methods and term co-occurrence methods are used. The results show that the theory of international competitiveness starts not from neoclassical theories of international trade, but from models of competition, even though competitiveness is mostly measured using trade/export performance. Krugman's work on imperfect competitive markets and increasing returns of scale plays a most important role in knowledge diffusion on international competitiveness. The scientific development of analyzed concept is connected with six topics: trade performance, technology, liberalization, environmental regulations, location and productivity. These results give us a background for conducting practical analyses of international competitiveness, especially ones using synthetic indices.
\end{abstract}

Keywords: international competitiveness, bibliometrics, citation network, term co-occurrence, main path analysis, key-routes path analysis.

JEL Classification: B2, C02, F40.

\section{Introduction}

The international competitiveness, despite its high popularity, has been described as one of the most misunderstood concepts in economics (Aiginger, Vogel 2015). A major problem is an abundance of definitions of the term in the literature, resulting from many different approaches to studying it (Bhawsar, Chattopadhyay 2015). It is a concept the understanding of which comes from different disciplines and the term covers a range of studies at various levels, i.e. mega, macro, mezzo and micro (Voinescu, Moisoiu 2015).

The theoretical debate about international competitiveness concentrates on the lack of theoretical foundations of many of its concepts and on the lack of a generally accepted theory of international competitiveness (Anca 2012). Comprehensive reviews of the existing literature on international competiveness are very rare. Although analyses by 
Banwet et al. (2002), followed by Bhawsar and Chattopadhyay (2015), provide critical reviews of the literature, they all deal with definitions, measurements and sources of various concepts in international competitiveness and always propose an integrated and eclectic approach, combining different schools of thought and multiple measurements as the most suitable way to study the topic.

The reviews of the international competitiveness literature published up to 2015 have one major drawback. They do not synthesize the existing literature and do not show the relationship between the different understandings of international competitiveness. Even the authors of the World Competitiveness Ranking highlight the difficulties in fitting competitiveness measurements to the conceptual framework of competitiveness (Bilbao-Osorio et al. 2013) and the absence of causality among the structural components of competitiveness rankings (Bris, Caballero 2015). However, among the latest publications in 2016 the first attempts at consolidating knowledge about the international competitiveness of countries (Castro-Gonzáles et al. 2016) and the competitiveness of firms (Peña-Vinces et al. 2016) are appearing. Therefore, as Castro-Gonzáles et al. (2016) state, the concept of international competitiveness is now under consolidation.

In this paper I propose an absolutely new approach in this area: bibliometric methods. This paper has the main aim of consolidating the state of the art of academic research on international competitiveness by making a bibliometric study of the literature published between 1945 and 2015. Citation data is collected from the ISI Web of Science Website, Scopus and Google Scholar, and is analysed using HistCite, VOSviewer and Pajek software. The main purpose is to accomplish the following objectives: to investigate the growth pattern of the international competitiveness literature, to track knowledge diffusion and determine the key research domains in the field, and finally to identify the path of the development of international competitiveness theory. The paper does not study international competitiveness from diverse points of view (at country, industry or company level) but focuses on the growth patterns of the international competitiveness literature.

\section{Data and methodology}

The bibliometric methods used in this paper can be divided into four groups.

First, to reflect changes in scientific output, the number of papers and the number of local citations of papers will be analysed. A local citation score (LCS) shows the number of citations of a paper in a (local) database which is created.

Second, to discover the core publications in the international competitiveness literature, citation network analysis is employed. Using HistCite software and based on cited references for each publication, a network between the most-cited works is generated. Histcite allows a historiograph to be drawn, in which the vertical axis represents time and the horizontal axis shows citation network nodes. Each node (a circle in the diagram) refers to a single publication with a unique number in the database, and the size of the node reflects the number of citations in the local database. Arrows show the relationship between the cited publications, i.e. from the publication analysed to previously 
published publications. To identify core publications in the historiograph, we look for big nodes with many arrows. In this paper, to create the historiograph the forty publications with the largest number of local citations are selected ${ }^{1}$.

Third, the citation network based on numbers of citations accumulated over time shows many paths connecting the oldest and newest most-cited publications, but which of the paths are the most important? I use a method called key-route path analysis to extract the main routes of the networks and to trace the main academic trajectory of an international competitiveness field (Liu, Lu 2012). To identify the key-route main paths, I use a freely available program called Pajek. The procedure of key-route main path analysis consists of three steps (Hung et al. 2014). First, the citation network of the 40 most-cited papers is analysed to identify two types of nodes: "source" nodes, which are cited but cite no other nodes, and "sink" nodes, which cite other nodes but are not cited. The paths I am interested in will begin at sources and always end at sinks. Second, links with the largest SPC (key-routes) value are selected, where SPC is the number of times the link is traversed if one exhausts the search from all the sources to all the sinks in the citation network. Third, the end node of each key route becomes the starting point from which to search for the links with the largest SPC. The process is continued until each key-route hits a sink. Simultaneously, a search backward from the start node of the key-route(s) is made until a source is hit. This procedure based on forward and backward searches guarantees that the desired links (with the largest SPC value) are included in the main paths.

Fourth, in addition to identifying the most important publications and the key-route paths in the scientific development of international competitiveness concepts, I also aim to identify the key research domains in international competitiveness studies. For this purpose, term co-occurrence analysis is employed. By applying the term co-occurrence technique, I analyse the distance between two terms, where a term is understood as a sequence of nouns in text documents. Terms in the local database records corresponding to publications on international competitiveness are extracted, with the record's fields, title, abstract and keywords being used as term sources. The term extraction, performed by means of the VOSviewer program, is done using a natural language processing algorithm (van Eck, Waltman 2011). A three-step term identification process is followed (van Eck, Waltman 2010). First, a linguistic filter is applied to the corpus in order to identify noun phrases. In the second step, the "unithood" of the noun phrases is calculated in order to identify semantic units and to eliminate noun phrases that start with uninteresting adjectives, such as first, many, new, and some. To measure unithood, the "likelihood" ratio is calculated, where the number of occurrences of the phrase, the

\footnotetext{
${ }^{1}$ The analysis is limited to 40 documents for three reasons: (1) because the most often cited documents can be considered to be central to the evolution of further research (Griffith et al. 1974) - in the local database the forty publications with the highest LCS represent $52.99 \%$ of the total number of local citations; (2) by selecting only the most cited papers I avoid loops in the citation network formed by all the retrieved documents; and (3) the limited sets (usually 30-40 publications) enable the results obtained by HistCite to be enhanced visually without overcrowding the visualizations (Lucio-Arias, Leydesdorff 2008).
} 
number of occurrences of the phrase without the first word, and the number of occurrences of the first word of the phrase are compared. VOSviewer software only chooses semantic units for further analysis if the natural logarithm of their likelihood ratio is less than -30 . In the third and final step, the "termhood" $\left(u_{k}\right)$ semantic units is measured, i.e. VOS calculates the degree to which the occurrences of a semantic unit are biased towards one or more topics:

where $p_{j}=\frac{P\left(t_{j} / u_{k}\right) / P\left(t_{j}\right)}{\sum_{j=1}^{J} P\left(t_{j} / u_{k}\right) / P\left(t_{j}\right)}$, and $\log 0$ is defined as 0 .

$$
\left(u_{k}\right)=\sum_{j=1}^{J} p_{j \log p_{j}}
$$

Next, the terms identified are placed on a map in such a way that the distance between any two items reflects the similarity between them. The degree of similarity is calculated using the association strength (Eq. 2) and the terms are located on the map by minimization of a weighted sum of the squared distances between the items (Eqs. 3 and 4) (van Eck, Waltman 2007):

$$
A s_{i j}=\frac{C_{i j}}{c_{i} c_{j}},
$$

where $c_{i j}$ is the number of co-occurrences of items $i$ and $j, c_{i}$ is the total number of cooccurrences of item $i$, and $c_{j}$ the total number of co-occurrences of item $j$.

$$
\begin{gathered}
V\left(X_{1} \ldots X_{N}\right)=\sum_{i<j} S_{i j}\left\|X_{i}-X_{j}\right\|^{2} \\
\frac{2}{n(n-1)} \sum_{i, j}\left\|X_{i}-X_{j}\right\|=1,
\end{gathered}
$$

where $n$ denotes the number of nodes in the network, $X_{i}$ denotes the location of node $i$ in a two-dimensional space, and $\left\|X_{i}-X_{j}\right\|$ denotes the Euclidean distance between nodes $i$ and $j$.

The terms identified can be grouped into clusters according to their similarity, and every cluster may be seen as one topic. To cluster the terms, VOSviewer maximizes the following function:

$$
V\left(c_{1} \ldots c_{n}\right)=\sum_{i<j} \delta\left(c_{i} c_{j}\right)\left(s_{i j}-\gamma\right),
$$

where $c_{i}$ denotes the cluster to which node $i$ is assigned, $\delta\left(c_{i} c_{j}\right)$ denotes a function that equals 1 if $c_{i}=c_{j}$ and 0 otherwise, and $\gamma$ denotes a resolution parameter that determines the level of detail of the clustering (the higher $\gamma$ is, the higher the number of clusters). Clustering terms allows these questions to be answered: how do these topics or these fields relate to each other, and how has a certain scientific domain developed over time? I understand very well the limitations related to the nature of bibliometric data, which are connected to the quality of citations (selective, secondary, negative and erroneous citations, self-citations), documents and journals (changes in journal titles, spelling differences and errors, inconsistencies related to the indexing of subjects, and incomplete 
coverage of the social sciences in the ISI Web). But the most significant constraint of the study is the limited sample size. The database created does not index books, book chapters or textbooks on international competitiveness. Some of these, e.g. Porter's book (1998), are considered bibles in international competitiveness studies. Additionally, the language of bibliometric analyses is English, which causes the important publications published in other languages to be ignored in this kind of analysis.

\section{Results of estimations}

The analysis begins with a descriptive analysis of the growth pattern of the international competitiveness literature. First, the distribution of published articles and their citations over time are analysed (Fig. 1).

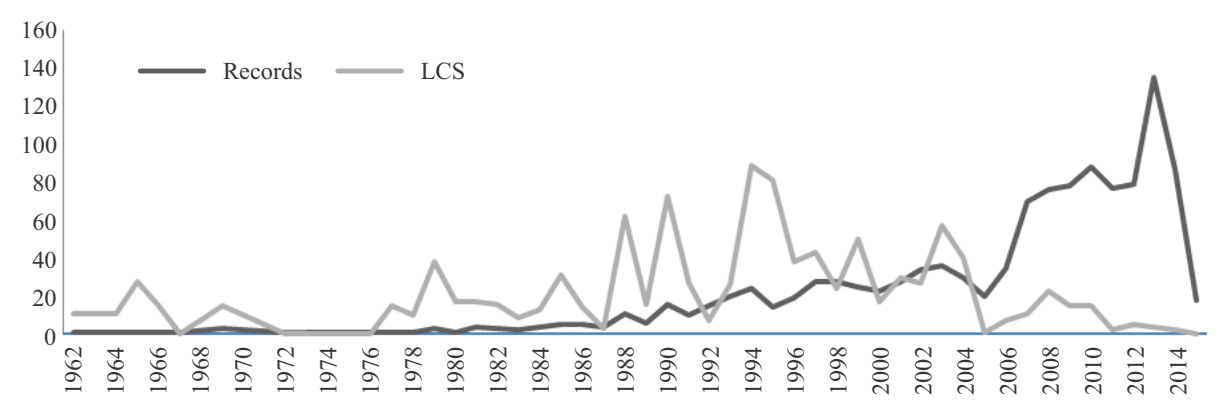

Fig. 1. Scientific productivity in the international competitiveness literature in the years 1945-2015

Source: own calculations on the local database.

Analysis of Figure 1 indicates that research on international competitiveness was and still is an important and popular subject of study in economics. Starting from the 1960s, interest in international competiveness grew constantly, with two breakthroughs in the number of publications $(1988,1994)$ and a boosting of interest in international competitiveness issues starting from 2007, which was mainly due to an explosion in competitiveness studies at the region and city levels and studies related to regulations, institutions and clustering processes and their impact on international competitiveness growth. In contrast to the increasing number of publications related to international competitiveness, the number of citations in the sample grew until 1994 and then unexpectedly diminished. One can hypothesize that the most important publications on international competitiveness were published two decades ago and the publications from the last decade do not contribute anything new or are poorly connected to the core publications from two decades before.

To check this hypothesis and simultaneously to identify the most important publications, a historiograph based on 40 publications with the highest LCS is created (Fig. 2). Taking into account only the node size (the number of local citations), the most significant publications in the evolution of research on international competitiveness are: Fagerberg's "International competitiveness" (No. 51), which found that technology and production 
capacity are more important for economic growth than price or the cost competitiveness of the economy (Fagerberg 1988) and Krugman's paper "Competitiveness - a dangerous obsession" (No. 131) on the unproductive discussion around international competitiveness, where international competitiveness is defined as "discussion on the theory of foreign trade, dressed in a new rhetoric" (Krugman 1994) ${ }^{2}$. Analysing the eight other most-cited publications, we can confirm the Krugman thesis that international competitiveness discourse is quite heavily focused on international trade determinants, such as trade liberalization (Balassa 1965), intra-industry effects (Melitz 2003), economies of scale, product differentiation (Dixit, Stiglitz 1977; Krugman 1979a, 1980), regulations and environmental policy (Tobey 1990; Jaffe et al. 1993; Barrett 1994; Porter, van der Linde 1995) and innovations (Greenhalgh 1990).

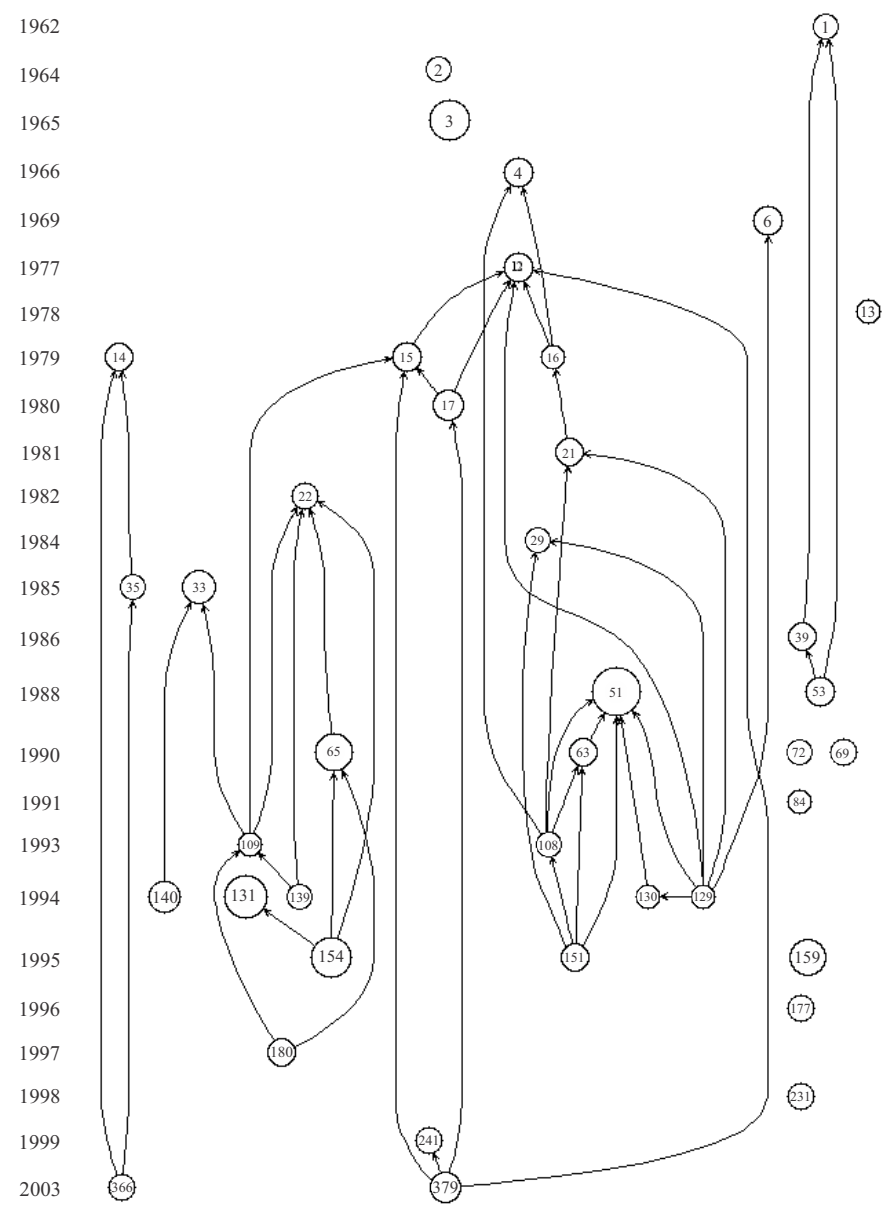

Fig. 2. Historiograph of the 40 most highly-cited publications in the local database Source: own calculation based on the local database.

\footnotetext{
${ }^{2}$ No. means the node number in the historiograph. Each node represents one publication from the local database, with a unique number.
} 
The arrow network in the historiograph shows that the roots of international competitiveness theory do not come from neoclassical theories of international trade. Although among the forty most-cited publications there are works by Balassa (Nos. 2 and 3) and Vernon (No. 4), they are only slightly connected with other publications, so the role of pioneering works in the evolution of international competitiveness should be attributed to publications from the end of the 1970s, i.e. works by Dixit and Stiglitz (No. 12) and Krugman (Nos.15, 16, and 17) (Balassa 1964, 1965; Vernon 1966; Dixit, Stiglitz 1977; Krugman 1979a, 1979b, 1980).

The most ground-breaking publications were published between 1985 and 1995 and the vertical shape of the historiograph suggests they still provide the most important theoretical basis for international competitiveness studies. These are works by Fagerberg (No. 51), Krugman (No. 131), Jaffe et al. (No. 154), Tobey (No. 65), Brander, Spencer (No. 33) and Porter (No. 133) (Brander, Spencer 1985; Fagerberg 1988; Tobey 1990; Jaffe et al. 1993; Krugman 1994; Porter, van der Linde 1995). The great majority of later publications contain references to these articles, but unexpectedly no paper published after 2005 is found among the 40 most-cited publications.

In the next step of the study, I apply key-route main path analysis to analyse more precisely all the paths in the historiograph created (Fig. 2) to find the most important ones. The historiograph in Figure 2 was created based on the number of local citations of documents, which accumulate over time, while main path analysis considers both the citations which a document receives and the documents it cites (Fig. 3). I use Pajek to determine the SPC values for each citation link and then to search for the key-route paths. Figure 3 presents the main paths for the 40 most often-cited documents in the "international competitiveness" set from the HistCite output. In Figure 3, I find eighteen publications, not necessarily the most highly-cited ones, which form the backbone of the international competitiveness network. Each node represents a paper, and the label for each paper contains its number in the local database, the last name of the first author (the other co-authors are omitted), the first initials of the author (in capital letters) and the year of publication. The size of the node indicates its SPC value.

The eighteen publications create five main paths, and the start, intermediate and final nodes of each path are presented in Table 1. For all the paths, the Dixit and Stiglitz (1977) publication "Monopolistic competition and optimum product diversity" plays the role of root. This underlines the role and character of competition in many markets, i.e. it is almost always imperfect, the products on the market are highly differentiated and firms have to face downward-sloping demand curves. The fact that the core paths start from Dixit and Stiglitz's publication allows confirmation of the thesis that the international competiveness concept comes from models of imperfect competition. The second step in the knowledge diffusion of international competiveness issues (common to almost all the paths) is Krugman's (1979b) article "Increasing returns, monopolistic competition and international trade". This focuses on the source of gains in international trade, where firms compete with each other in an imperfect competitive market and increasing returns to scale decide trade advantages. The presence of Krugman's publication in the main paths indicates that the international competitiveness concept 
is neatly connected to and often measured via international trade performance (in all the key routes).

Starting from the beginning of the nineties, the paths in international competitiveness diverge. Path No. 1 connects international competitiveness (understood as export performance) with technology. Publications written by Krugman (1979a), Soete (1981), Amendola et al. (1993), and Amable and Verspagen (1995) indicate that technological capacities (patents, investments in technology) are a major determinant in shaping the dynamics of exports (Krugman 1979a; Soete 1981; Amendola et al. 1993; Amable, Verspagen 1995). Path No. 2 represents publications in which international competitiveness measured by international trade performance is related to liberalization issues. The publications in path No. 3 focus on the impact of domestic environmental regulations on the international trade flow. Path No. 4 consists of papers related to the determinants of production location, such as the size of domestic markets, production concentration and its impact on international competitiveness. The last path, No. 5, is the shortest one, and it connects two economic categories: productivity and international trade growth. Publications in this path focus on the role of firm-level productivity in boosting export activity among firms.

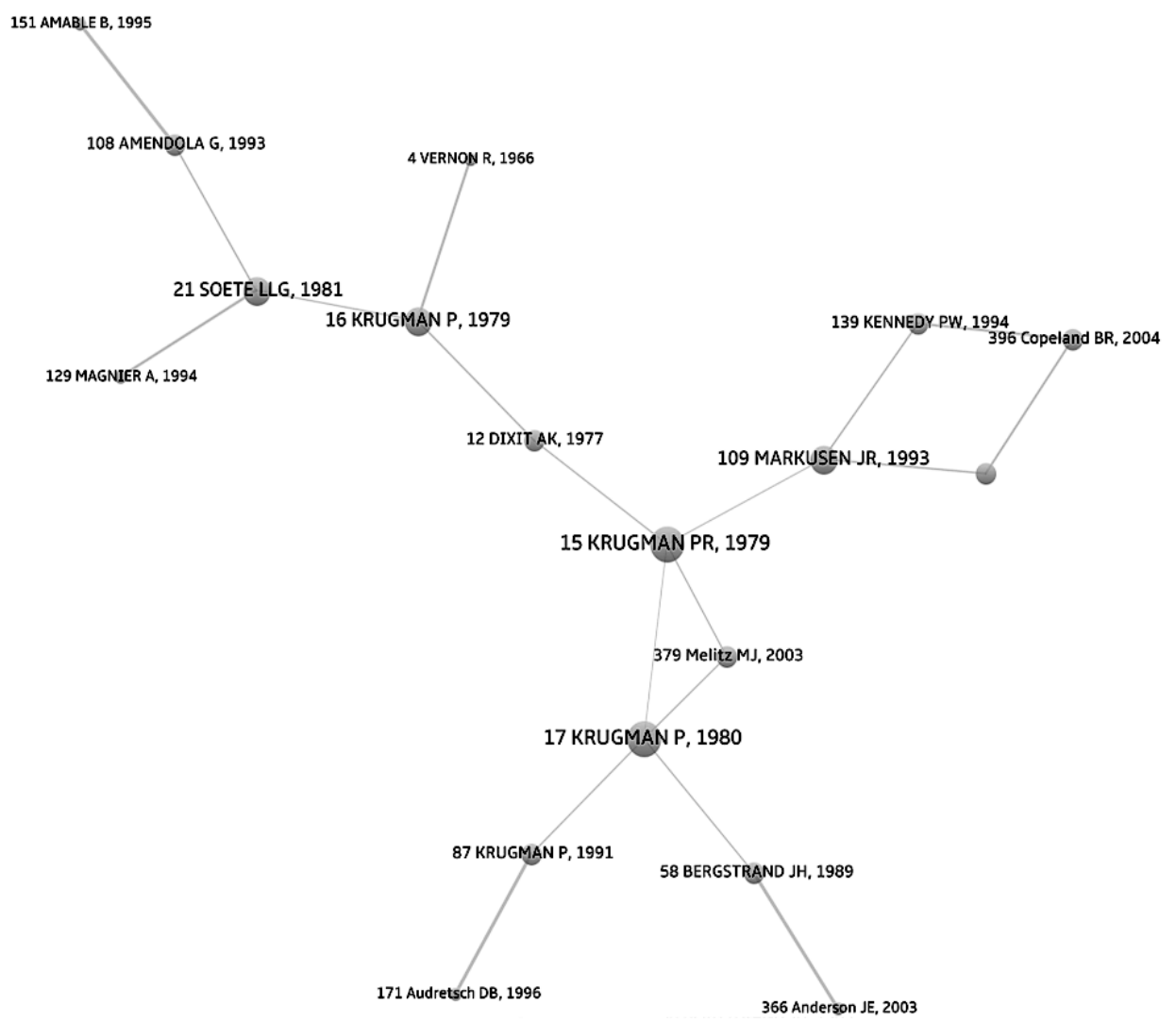

Fig. 3. The key-route main paths of international competitiveness, based on the top 120 links Source: own calculation using Pajek software; visualization from Vosviewer software. 
Table 1. Five main paths in international competitiveness

\begin{tabular}{|c|c|c|c|c|c|}
\hline $\begin{array}{l}\text { Key } \\
\text { route }\end{array}$ & $\begin{array}{l}\text { Step } 1 \\
\rightarrow\end{array}$ & $\begin{array}{c}\text { Step } 2 \\
\rightarrow\end{array}$ & $\begin{array}{c}\text { Step } 3 \\
\rightarrow\end{array}$ & $\begin{array}{c}\text { Step } 4 \\
\rightarrow\end{array}$ & Step 5 \\
\hline No 1 & $\begin{array}{l}\text { Dixit and } \\
\text { Stiglitz } 1977\end{array}$ & Krugman 1979a & Soete 1981 & $\begin{array}{l}\text { Amendola et al. } \\
1993\end{array}$ & $\begin{array}{l}\text { Amable and } \\
\text { Verspagen } 1995\end{array}$ \\
\hline No2 & $\begin{array}{l}\text { Dixit and } \\
\text { Stiglitz } 1977\end{array}$ & Krugman 1979b & Krugman 1980 & Bergstrand 1989 & $\begin{array}{l}\text { Anderson and } \\
\text { Wincoop } 2003\end{array}$ \\
\hline No 3 & $\begin{array}{l}\text { Dixit and } \\
\text { Stiglitz } 1977\end{array}$ & Krugman 1979b & $\begin{array}{l}\text { Markusen and } \\
\text { Rutherford } 1994\end{array}$ & $\begin{array}{l}\text { Kennedy } 1994 \text { or } \\
\text { van Beers and van } \\
\text { den Bergh } 1997\end{array}$ & $\begin{array}{l}\text { Copeland and } \\
\text { Taylor } 2004\end{array}$ \\
\hline No 4 & $\begin{array}{l}\text { Dixit and } \\
\text { Stiglitz } 1977\end{array}$ & Krugman 1979b & Krugman 1980 & Krugman 1991 & $\begin{array}{l}\text { Audretsch and } \\
\text { Feldman } 1996\end{array}$ \\
\hline No 5 & $\begin{array}{l}\text { Dixit and } \\
\text { Stiglitz } 1977\end{array}$ & $\begin{array}{l}\text { Krugman } 1979 b \\
\text { or Krugman } 1980\end{array}$ & Melitz 2003 & $\mathrm{x}$ & $\mathrm{x}$ \\
\hline
\end{tabular}

Source: own calculation using Pajek software.

The key route analysis reveals several important things: the concept of international competitiveness comes directly from imperfect competition models and is mostly defined and measured by international trade/export performance. Although the most-cited publications related to international competitiveness are by Krugman, Fagerberg and Balassa, only Krugman's works are significant in the knowledge diffusion paths of international competitiveness. These main paths shows that the scientific development of the international competitiveness literature concentrate on five main economic categories: technology, liberalization, environmental regulations, location and productivity. Because the main-path analysis is performed for only the 40 most often-cited documents in the "international competitiveness" set, some significant research topics related to international competitiveness may be omitted. To verify this, I use a quite different method: word co-occurrence analysis, which is based not only on the most-cited documents but on all the publications in the local database.

In this analysis, the titles, abstracts and keywords from 1174 publications are used as term sources and 18823 unique terms are extracted from the local database. A minimum number of occurrences of 12 is set, and 444 terms meet the threshold. Among the 444 terms, relevance scores are calculated by VOSviewer and then the $60 \%$ most relevant terms are selected. Finally, 266 terms are obtained, from which terms not germane to the goals of the analysis are excluded, such as specific place names, general statistical terms and units of measurement of such things as time, quantity and rate. Figure 4 shows the term co-occurrence map, where each term is represented by a circle, and the diameter of the circle and the size of its label represent the frequency of the term, its proximity to another term indicates the degree of relatedness of the two terms, and its colour represents the cluster to which it conceptually belongs. 
Analysis of Figure 4 indicates that trade (the largest circle) is the most frequently mentioned word, followed by the phrases international trade, export, cost, price, knowledge and FDI. There are clearly four clusters in the figure. The first cluster can be dubbed the "trade cluster". This cluster groups together terms associated with trade: trade flow and international trade. Here, we can distinguish two key topics: the influence of regulations and environmental policies, and cost changes. The second cluster, which can be called the "export cluster", shows the importance of the following topics: prices, exchange rates, and differences in income or in GDP level vis-à-vis export performance. The trade and export clusters are very close to each other, and from the theoretical point of view they relate to analyses of international competitiveness in the light of foreign trade theories. The third cluster, named the "location cluster", points to the importance of location, broadly defined as economic distance, in the growth of international competitiveness. In this research area the impact of FDI, openness of the economy and economies of scale on the position of economies, industries and enterprises in the world market are mainly analysed. The last cluster, called "knowledge \& institutions", represents research domains which are the furthest from the mainstream of the analyses represented by the first three clusters. The first of these domains is related to the role of education, knowledge and human capital in increasing international competitiveness. In the second one, the impact of the quality of institutions and the business environment are analysed. The third research area groups together terms associated with the regional aspect of international competitiveness, with a particular emphasis on city competitiveness.

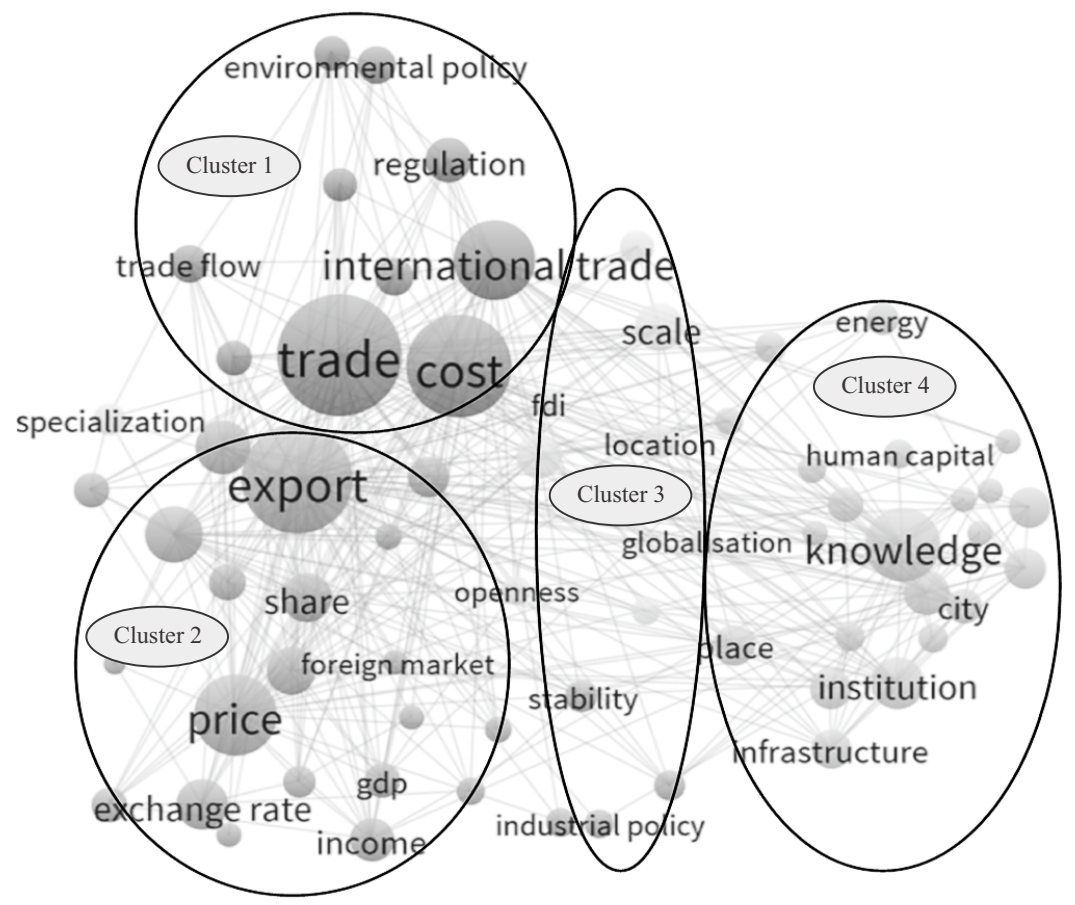

Fig. 4. Four clusters in the international competitiveness literature (1945-2015) by term co-occurrence analysis Source: Own calculation on Vosviewer software. 
To check whether international competitiveness research domains have changed much in the last decade, I conduct term co-occurrence analysis once more, this time only based on documents published between 2004 and 2015 (Fig. 5). Analysis of Figure 5 shows quite large changes in the terms co-occurring in the literature from the last 11 years analysed. One can speak about a polarization of research domains in the international competitiveness literature. Two dominant clusters can be distinguished which together group the majority of key topics. The first cluster, which is still the most important one, can be dubbed "traditional", because it groups the most frequently occurring terms associated with exports and international trade flows (such as cost, price, exchange rate, income and FDI).

The second big cluster, named "knowledge, institutions and environment", represents research domains which became the mainstream in international competitiveness analyses in the last decade. The most recent publications on international competitiveness are related to the role of education, knowledge, human capital or R\&D investments in increasing international competitiveness, or the impact of the quality of institutions and the business environment are analysed. Additionally, other key topics in recent international competitiveness studies are the relationship between environmental regulations and trade/export growth and the regional aspect of international competitiveness, with a particular emphasis on city competitiveness. It is worth noting that the network of lines between the terms in cluster 2 is much thicker than in cluster 1, which indicates that the terms grouped in the second cluster co-occur in documents more often than those in the first.

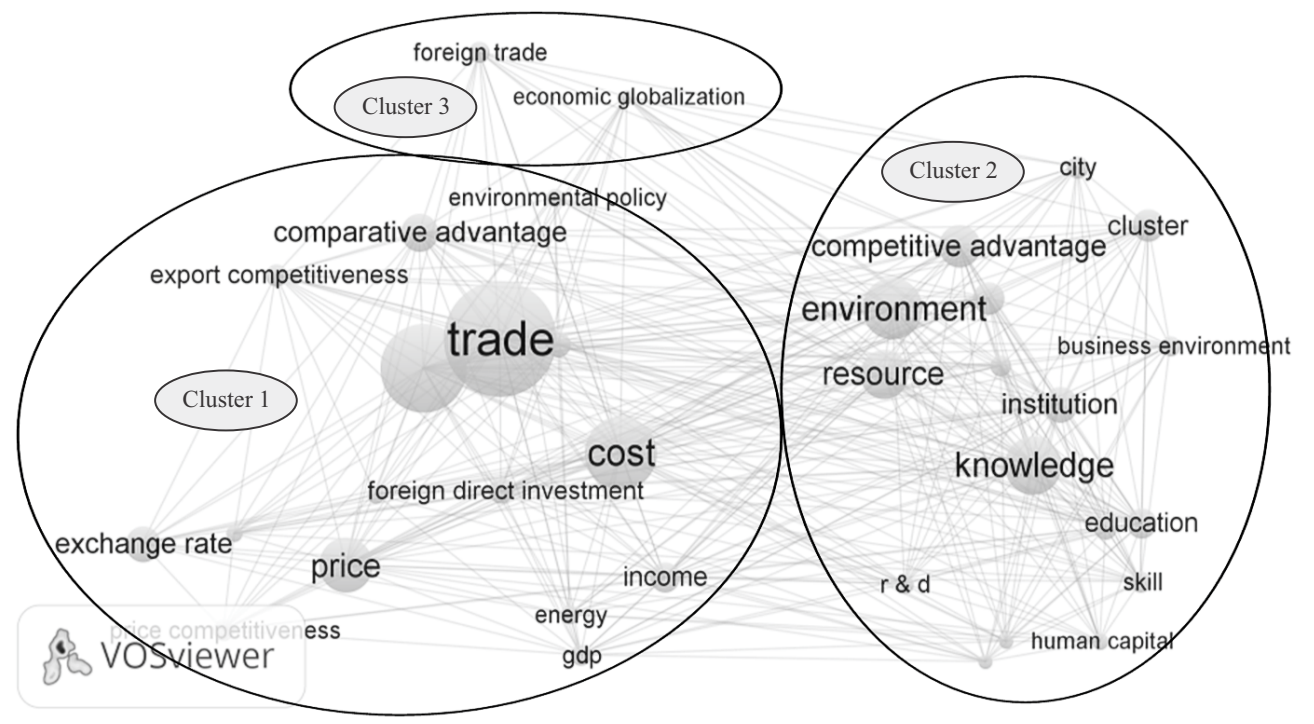

Fig. 5. Four clusters in the international competitiveness literature (2004-2015)

by term co-occurrence analysis

Source: Own calculation using Vosviewer software. 
The third cluster is a small one and consists of terms related to the globalization process and its impact on international competitiveness growth. The importance of the terms in cluster 3 , shown by the size of the circle and the line density, is less than in the first two clusters.

\section{Conclusions}

There are still many open questions related to the definition of international competitiveness, competitiveness factors, and practical approaches to foster international competitiveness and their applicability. Existing literature reviews reveal an obvious lack of consensus regarding the exact meaning of international competitiveness and ways to measure it. They suggest that international competitiveness can be considered at different levels of aggregation: firm, industry or country. More recent theoretical debates concentrate on the conceptual complexity of international competitiveness, with existing approaches ranging from an exclusively microeconomic perspective (Krugman's approach) to an all-encompassing micro- and macro-economic perspective (WEF rankings, IMD World Competitiveness Yearbook). Contemporary theoretical controversies concern the non-existence of international competitiveness theory. All this mean that the validity of empirical international competitiveness analyses, especially those based on the popular World Economic Forum methodology, is undermined due to a lack of a good theoretical basis for the selection of variables.

The originality of the analysis conducted here lies in synthesizing the existing theoretical and empirical literature and investigating the growth pattern of the international competitiveness literature by identifying the core publications/authors and the key research domains and their changes over time. This is a very different approach to the rare previous studies of the international competitiveness literature and can lead to attempts to formulate a theory of international competitiveness by identifying the key-route paths in the development of international competitiveness concepts.

The analyses conducted allow many of the hypotheses which can be found in the scientific theoretical discourse on international competitiveness to be confirmed or rejected. It has been found that international competitiveness theory starts not from neoclassical theories of international trade, but from models of imperfect competition (Dixit and Stiglitz's model), even though it is mostly measured using trade/export performance. Krugman's work on imperfect competitive markets and increasing returns of scale plays a most important role in the knowledge diffusion on international competitiveness. It has also been found that Krugman's criticism of the international competitiveness concept at the macro level contributed to the development of international competitiveness theory through a theoretical reorientation and polarization of international competitiveness concepts in the last decade.

These results have many practical implications. They constitute a background for conducting empirical analyses of international competitiveness, especially ones using synthetic indices based on many variables. The researches should pay attention to the changing weights of the variables over time and to the increased influence of human 
capital, innovation and the institutional environment on international competitiveness. In addition, the results give the methodological base for international competitiveness analysis rooted in growth, location and economic geography theories.

This study should be regarded as preliminary and requiring verification. It is hoped, however, that it will have an important role in discussion on the evolution of international competitiveness theory among disciples of economics.

\section{Funding}

This work was supported by National Science Centre in Poland [grant number DEC2011/03/D/HS4/00861].

\section{Disclosure statement}

In accordance with Taylor \& Francis policy and my ethical obligation as a researcher, I am reporting that I have received funding from National Science Centre in Poland. No potential conflict of interest may arise from this fact.

\section{References}

Aiginger, K.; Vogel, J. 2015. Competitiveness: from a misleading concept to a strategy supporting beyond GDP goals, Competitiveness Review 25(5): 497-523.

https://doi.org/10.1108/CR-06-2015-0052

Amable, B.; Verspagen, B. 1995. The role of technology in market shares dynamics, Applied Economics 27(2): 197-204. https://doi.org/10.1080/00036849500000024

Amendola, G.; Dosi, G.; Papagni, E. 1993. The dynamics of international competitiveness, Weltwirtschaftliches Archiv 129(3): 451-471. https://doi.org/10.1007/BF02707997

Anca, H. D. 2012. Literature review of the evolution of competitiveness concept, Annals of the University of Oradea, Economic Science Series 21(1): 41-46.

Anderson, J. E.; Wincoop, E. 2003. Gravity with gravitas: a solution to the border puzzle, American Economic Review 93(1): 170-192. https://doi.org/10.1257/000282803321455214

Audretsch, D. B.; Feldman, M. P. 1996. R\&D spillovers and the geography of innovation and production, The American Economic Review 86(3): 630-640.

Balassa, B. 1964. The purchasing-power parity doctrine: a reappraisal, Journal of Political Economy 72(6): 584-596. https://doi.org/10.1086/258965

Balassa, B. 1965. Trade liberalisation and "revealed" comparative advantage, Manchester School 33(2): 99-123. https://doi.org/10.1111/j.1467-9957.1965.tb00050.x

Banwet, D. K.; Momaya, K.; Shee, H. K. 2002. Competitiveness: perceptions, reflections and directions, IIMB Management Review 14(3): 105-116.

Barrett, S. 1994. Self-enforcing international environmental agreements, Oxford Economic Papers 46: 878-94.

Bergstrand, J. H. 1989. The generalized gravity equation, monopolistic competition, and the factor-proportions theory in international trade, The Review of Economics and Statistics 71(1): 143-153. https://doi.org/10.2307/1928061

Bhawsar, P.; Chattopadhyay, U. 2015. Competitiveness: review, reflections and directions, Global Business Review 16(4): 665-679. https://doi.org/10.1177/0972150915581115 
Bilbao-Osorio, B.; Blanke, J.; Campanella, E.; Crotti, R.; Drzeniek-Hanouz, M.; Serin, C. 2013. Assessing the sustainable competitiveness of nations [online], [cited April 2015]. Available from Internet: www3.weforum.org/docs/GCR2013-14/GCR_Chapter1.2_2013-14.pdf

Brander, J. A.; Spencer, B. J. 1985. Export subsidies and international market share rivalry, Journal of International Economics 18(1-2): 83-100. https://doi.org/10.1016/0022-1996(85)90006-6

Bris, A.; Caballero, J. 2015. Reconsidering the Fundamentals of Competitiveness [online], [cited September 2015]. Available from Internet: http://www.imd.org/research/challenges/upload/ TC028-15-redefining-competitivness-PDF.pdf

Castro-Gonzáles, S.; Peña-Vinces, J. C.; Guillen, J. 2016. The competitiveness of Latin-American economies: consolidation of the double diamond theory, Economic Systems 40(3): 373-386. https://doi.org/10.1016/j.ecosys.2015.10.003

Copeland, B. R.; Taylor, M. S. 2004. Trade, growth, and the environment, Journal of Economic Literature 42(1): 7-71. https://doi.org/10.1257/.42.1.7

Dixit, A. K.; Stiglitz, J. E. 1977. Monopolistic competition and optimum product diversity, The American Economic Review 67(3): 297-308.

Fagerberg, J. 1988. International competitiveness, The Economic Journal 98(391): 355-374. https://doi.org/10.2307/2233372

Greenhalgh, C. 1990. Innovation and trade performance in the United Kingdom, The Economic Journal 100(400): 105-118. https://doi.org/10.2307/2234188

Griffith, B. C.; Small, H. G.; Stonehill, J. A.; Dey, S. 1974. The structure of scientific literatures II: toward a macro- and microstructure for science, Social Studies of Science 4(4): 339-365. https://doi.org/10.1177/030631277400400402

Hung, S.-C.; Liu, J. S.; Lu, L. Y. Y.; Tseng, Y.-C. 2014. Technological change in lithium iron phosphate battery: the key-route main path analysis, Scientometrics 100(1): 97-120.

https://doi.org/10.1007/s11192-014-1276-9

Jaffe, A. B.; Trajtenberg, M.; Henderson, R. 1993. Geographic localization of knowledge spillovers as evidenced by patent citations, The Quarterly Journal of Economics 108(3): 577-598. https://doi.org/10.2307/2118401

Kennedy, P. W. 1994. Equilibrium pollution taxes in open economies with imperfect competition, Journal of Environmental Economics and Management 27(1): 49-63.

https://doi.org/10.1006/jeem.1994.1025

Krugman, P. 1979a. A model of innovation, technology transfer, and the world distribution of income, Journal of Political Economy 87(2): 253-266. https://doi.org/10.1086/260755

Krugman, P. 1979b. Increasing returns, monopolistic competition, and international trade, Journal of International Economics 9(4): 469-479. https://doi.org/10.1016/0022-1996(79)90017-5

Krugman, P. 1980. Scale economies, product differentiation, and the pattern of trade, The American Economic Review 70(5): 950-959.

Krugman, P. 1991. Increasing returns and economic geography, Journal of Political Economy 99(3): 483-499. https://doi.org/10.1086/261763

Krugman, P. 1994. Competitiveness: a dangerous obsession, Foreign Affairs 73(2): 28-44. https://doi.org/10.2307/20045917

Liu, J. S.; Lu, L. Y. Y. 2012. An integrated approach for main path analysis: development of the Hirsch index as an example, Journal of the American Society for Information Science 63(3): 528-542. https://doi.org/10.1002/asi.21692

Lucio-Arias, D.; Leydesdorff, L. 2008. Main-path analysis and path-dependent transitions in HistCite ${ }^{\mathrm{TM}}$-based historiograms, Journal of the American Society for Information Science 59(12): 1948-1962. https://doi.org/10.1002/asi.20903 
Markusen, J. R.; Rutherford, T. F. 1994. Discrete plant-location decisions in an applied generalequilibrium model of trade liberalization, Weltwirtschaftliches Archiv 130(1): 133-151.

https://doi.org/10.1007/BF02706013

Melitz, M. J. 2003. The impact of trade on intra-industry reallocations and aggregate industry productivity, Econometrica 71(6): 1695-1725. https://doi.org/10.1111/1468-0262.00467

Peña-Vinces, J. C.; Casanova, L.; Guillen, J.; Urbano, D. 2016. International competitiveness of small and medium-sized enterprises: Peru, a Latin-American emerging market, Emerging Markets Finance and Trade (in press). http://dx.doi.org/10.1080/1540496X.2016.1156525

Porter, M. E. 1998. Competitive advantage of nations. New York: Free Press.

https://doi.org/10.1007/978-1-349-14865-3

Porter, M. E.; van der Linde, C. 1995. Toward a new conception of the environment-competitiveness relationship, Journal of Economic Perspectives 9(4): 97-118.

https://doi.org/10.1257/jep.9.4.97

Soete, L. L. G. 1981. A general test of technological gap trade theory, Weltwirtschaftliches Archiv 117(4): 638-660. https://doi.org/10.1007/BF02708115

Tobey, J. A. 1990. The effects of domestic environmental policies on patterns of world trade: an empirical test, Kyklos 43(2): 191-209. https://doi.org/10.1111/j.1467-6435.1990.tb00207.x

van Beers, C.; van den Bergh, J. C. J. M. 1997. An empirical multi-country analysis of the impact of environmental regulations on foreign trade flows, Kyklos 50(1): 29-46.

https://doi.org/10.1111/1467-6435.00002

van Eck, N. J.; Waltman, L. 2007. Bibliometric mapping of the computational intelligence field, International Journal of Uncertainty, Fuzziness and Knowledge-Based Systems 15(05): 625-645. https://doi.org/10.1142/S0218488507004911

van Eck, N. J.; Waltman, L. 2010. Software survey: VOSviewer, a computer program for bibliometric mapping, Scientometrics 84(2): 523-538. https://doi.org/10.1007/s11192-009-0146-3

van Eck, N. J.; Waltman, L. 2011. Text mining and visualization using VOSviewer, ISSI Newsletter 7(3): 50-54.

Vernon, R. 1966. International investment and international trade in the product cycle, The Quarterly Journal of Economics 80(2): 190-207. https://doi.org/10.2307/1880689

Voinescu, R.; Moisoiu, C. 2015. Competitiveness, theoretical and policy approaches. Towards a more competitive EU, Procedia Economics and Finance 22: 512-521.

https://doi.org/10.1016/S2212-5671(15)00248-8

Magdalena OLCZYK is an Assistant Professor of Economics at Gdansk University of Technology. She specializes in the competitiveness theory at macro and mezzo level, innovation \& globalization issues and structural change in transitions economics. She is a member of Polish Economic Society, Baltic Sea Academy, and also the Eastern European Business and Economics Journal board. The project manager and participant of many scientific research projects financed by EU funds, the National Science Centre in Poland and National Bank of Poland. 